\title{
Development of pediatric neurosurgical service at Dr. Soetomo Hospital, Surabaya, Indonesia \\ by Muhammad Parenrengi
}

Submission date: 29-Nov-2018 11:28AM (UTC+0800)

Submission ID: 1046845342

File name: urgical_service_at_dr._soetomo_hospital,_surabaya,_indonesia.pdf (2.73M) Word count: 3336

Character count: 19059 


\title{
Development of pediatric neurosurgical service at Dr. Soetomo Hospital, Surabaya, Indonesia
}

\author{
Wihasto Suryaningtyas ${ }^{1}$ (C) $\cdot$ Muhammad Arifin $^{1} \cdot$ Agus Turchan $^{1} \cdot$ Abdul Hafid Bajamal $^{1}$
}

Received: 18 May 2017/Accepted: 26 June 2017/Published online: 10 July 2017

C) Springer-Verlag GmbH Germany 2017

\begin{abstract}
$_{3}$
Purpose This review traces the history of pediatric neurost 3 gery at Dr. Soetomo General Hospital (DSGH) and its role in advancing the field of pediatric neurosurgery.

Methods The history, the founding fathers, and the next generations of the pediatric neurosurgery in DSGH were traced back from original sources and authors' life stories.

Result Pediatric neurosurgical service at DSGH has its own unique perspective being a pediatric service in general hospital setting. It serves second largest city of Indonesia - the fifth most populated country in the world. Historical vignette and future perspectives are narratively presented.

Conclusion As a pediatric neurosurgical service at general hospital in developing country, its development deserves a special mention.
\end{abstract}

Keywords Pediatric neurosurgical service $\cdot$ Frontoethmoidal encephalocele (FEEM) - Endoscopic neurosurgery ·

Developing country

\section{Introduction}

Indonesia has more than 250 million people with one third of the population is pediatric age group. In Indonesia, there is no specialized children's hospital that runs full spectrum of specialty services dedicated to sick children. Most, if not all, of pediatric surgical cases will be managed in general hospital along

$凶$ Wihasto Suryaningtyas

wihasto-s@ fk.unair.ac.id

1 Department of Neurosurgery, Airlangga University Faculty of Medicine-Dr. Soetomo General Hospital, Surabaya, Indonesia with its adult counterpart. Surabaya, the second largest city in Indonesia, has 3.5 million population. There are more than 15 public and private hospitals serving in Surabaya. Dr. Soetomo General Hospital (DSGH) is the only major tertiary care center in Surabaya with 1500 beds serving children and adults patient from the city and eastern part of Indonesia (Fig. 1a). As the highest and largest referral hospital, pediatric neurosurgical service at DSGH receives cases with moderate and high severity level. It is a demanding service, despite the limitations in facility. Geographical closeness and historical background make DSGH also serving as teaching hospital for Universitas Airlangga Faculty of Medicine (Fig. 1b). Medical professional education for undergraduate students and residents takes place in the premises. The word "ideal" or "perfect" still requires a huge effort to address challenges in the evolution of the service.

\section{Days of pioneers}

Dr. Basoeki Wirjowidjojo, the pioneer neurosurgeon, started the first neurosurgical service in Surabaya. He worked after he finished his neurosurgery training in Tilburg, Netherland, in 1959. In 1971 to 1979 , he sent three doctors to learn neurosurgery in Nijmegen, Netherland, namely Muhammad Sajid Darmadipura, Umar Kasan, and Abdul Hafid Bajamal. Until 1975, Dr. Wirjowidjojo looked after neurosurgery service alone while waiting for Dr. Darmadipura finished his training. Dr. Darmadipura finished the training in 1975 and helped Dr. Wirjowidjojo to take care the service. Dr. Kasan finished his training in 1979 and Dr. Bajamal finished in 1983. Neurosurgery had adequate work force with four neurosurgeons (Fig. 2). In early years, they did all cases as general neurosurgeons including pediatric. Concentrating into one subspecialty was not feasible. To avoid conflict that may arise from unbalanced workload and its financial consequences, 
11. 1 a The front gate view of Dr. Soetomo General Hospital, Surabaya, (2016). b The front view of Universitas Airlangga Faculty of Medicine (2016)

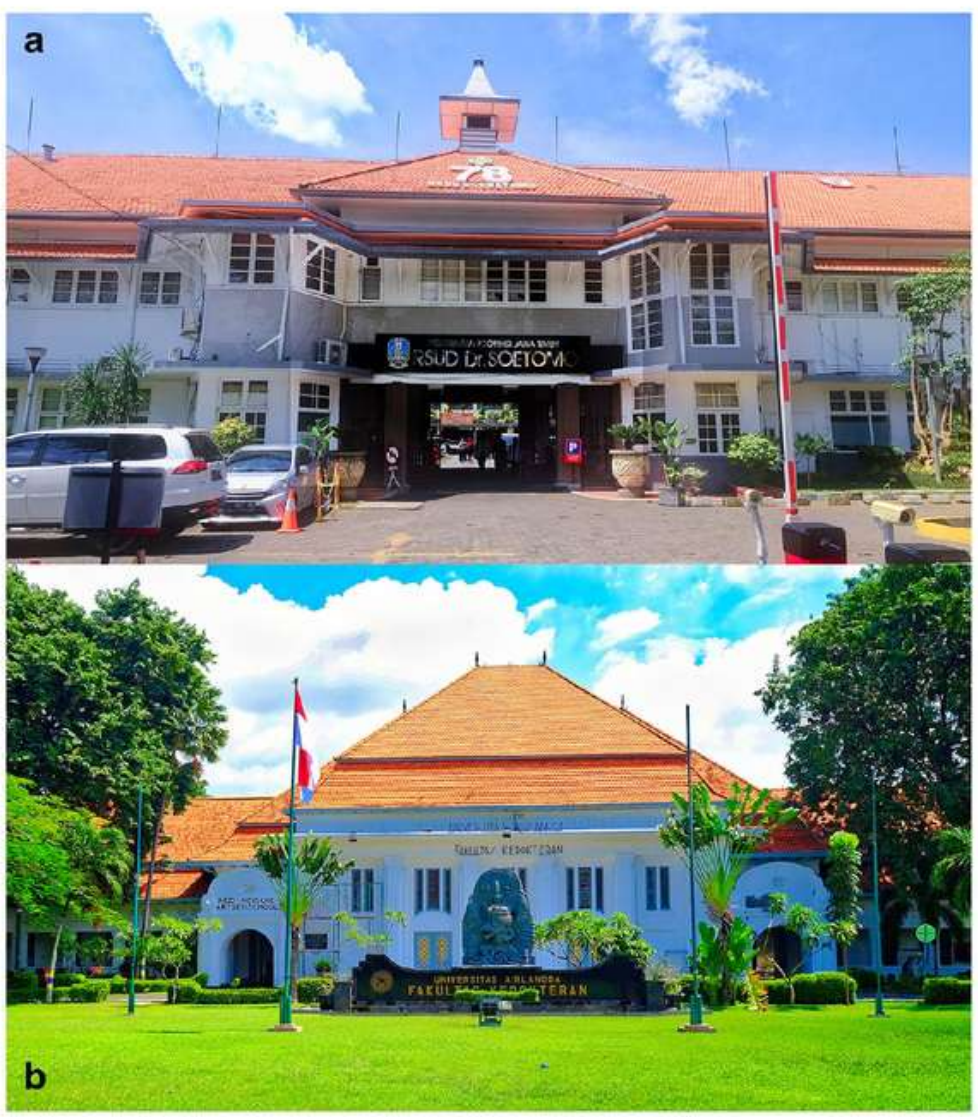

they made an agreement to share the workload, pooled all the income from clinical work, and shared among four neurosurgeons. This kind of practice plan was the first of its kind in the hospital. Over time, each member showed interest in specific field. Neurovascular, brain tumor, and spine surgery attracted more interest than other areas, including pediatric and trauma.

Dr. Abdul Hafid Bajamal realized that pediatric patients needed special attention. In 1990, he attended pediatric neurosurgical service in 10. as Children's Hospital, Houston, for one and a half months, learning the state-of-art of pediatric neurosurgery, under supervision of Dr. John P Laurent. High prevalence of frontoethmoidal encephalomeningocele (FEEM) drove him to visit Chulalangkorn Hospital, Bangkok, Thailand, to refine the surgical technique on FEEM using the Chula technique [1]. Technically, the surgery for FEEM in Surabaya changed since then. The old technique of extracranial approach was abandoned by the younger generation of neurosurgeons.

\section{The next generation}

The increasing volume of cases and the surfacing necessity of more staff led to recruitment of newly graduated neurosurgeons. In 1995, Muhamad Arifin (Fig. 3) and Agus Turchan (Fig. 4), who had just graduated as neurosurgeon from Universitas Airlangga Faculty of Medicine-DSGH, were offered to join the department. Dr. Agus Turchan was prepared to pursue more exposure on functional neurosurgery and to develop epilepsy surgery program for adult and pediatric once he returned from Cologne, Germany. He is now the head of Department of Neurosurgery at DSGH. Dr. Arifin was expected to take care of the congenital neurosurgical disease. He was sent to learn craniofacial surgery in Adelaide, Australia, and neuroendoscopy course in Kuala Lumpur, Malaysia. He never had a formal fellowship experience, but his dexterity in surgical skill and his long experience taking care the pediatric cases gave him ample advantages. The advance techniques on encephalocele and craniosynostosis were introduced to give pediatric patients an extra benefit from surgery. Transposition, remodeling, and plastic techniques to rebuild the deformed skull due to craniosynostosis were applied to replace simple suturectomy techniques. Since then, Dr. Arifin was considered to take care most of the central nervous system (CNS) congenital anomalies. At this era, the concept of pediatric neurosurgery was only conserved to congenital neurosurgery. Other diseases affecting the child such as neurovascular disease, brain tumor, 


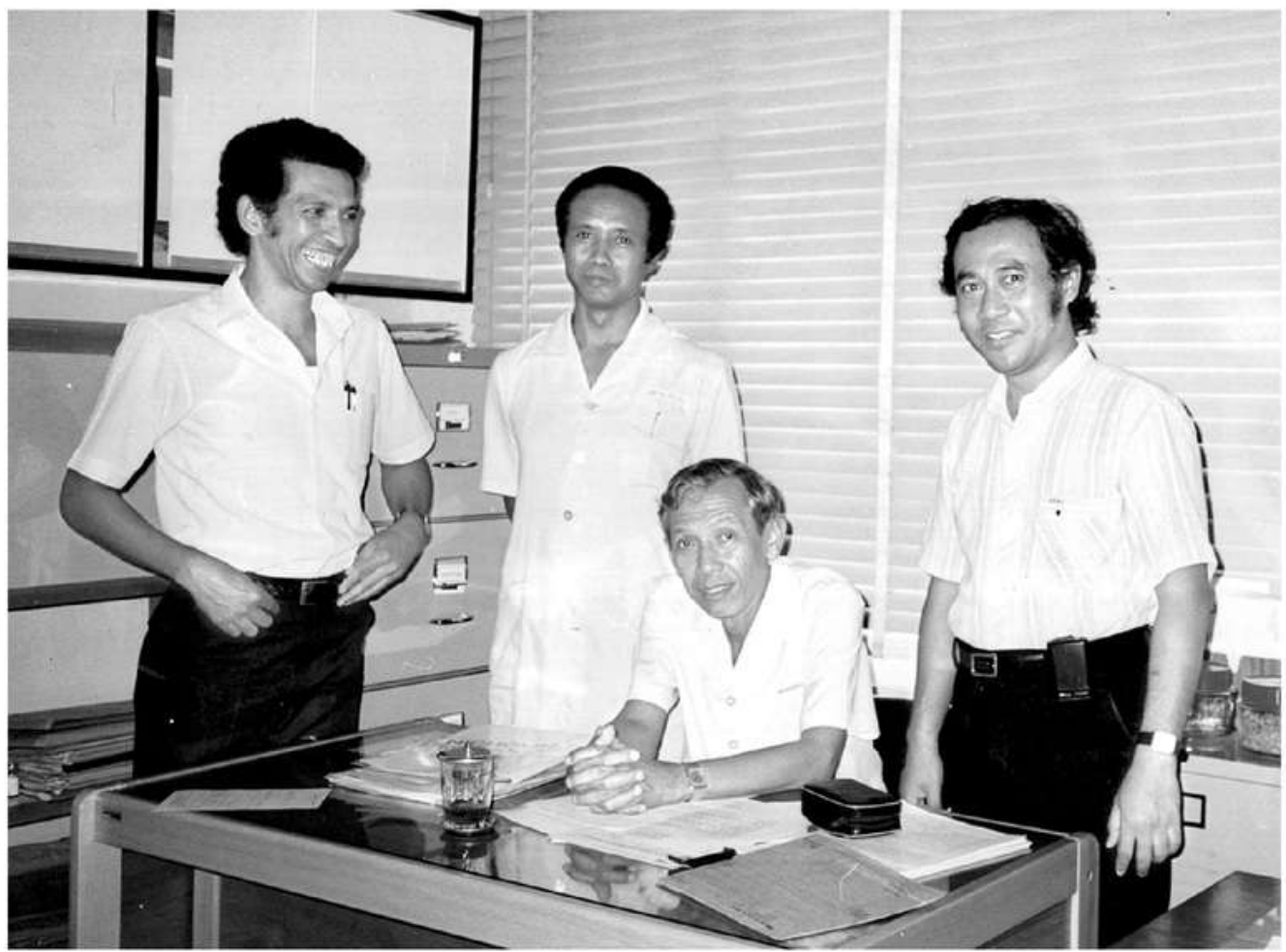

Fig. 2 The four neurosurgeons, left to right Dr. Bajamal, Dr. Darmadipura, Dr. Wirjowidjojo (seated), and Dr. Kasan (1989)

spinal problems, and brain trauma were taken care by general neurosurgeons who worked also for adult.

Anticipating an increasing load due to full pediatric service, additional fulltime pediatric neurosurgeon became feasible. Dr. Wihasto Suryaningtyas (Fig. 5) was recruited in 2008 right after his graduation from neurosurgery residency training in Universitas Airlangga Faculty of Medicine-DSGH, Surabaya. He showed his interest in pediatric neurosurgical cases since he was in training. He proposed to Dr. Arifin that pediatric neurosurgery service was not constrained in congenital anomalies and hydrocephalus but also included pediatric brain tumor, neurovascular disease, spine, and functional neurosurgery including epilepsy surgery. The old paradigm that pediatric equaled congenital changed to new one that pediatric neurosurgery equaled all neurosurgical cases in pediatric age group (under 18 years old). In 2009, Dr. Suryaningtyas received International Traveling Fellowship in Pediatric Neurosurgery grant from American Association of Neurological Surgeons (AANS). Under Dr. R. Michael Scott, he stayed in Boston as observer fellow in Children's Hospital Boston for 3 months.

Back to 2005, Dr. Sury gingtyas met Dr. David Fairholm who worked as volunteer for Foundation for International Education in Neurological Surgery (FIENS). The original purpose of Dr. Fairholm visit in Surabaya was to help the Program Director of Neurosurgery Residency Training to review, revise, and develop a more advance neurosurgery training program. He also worked as clinical instructor and intensely involved in residency teaching program. Dr. Suryaningtyas' intention to pursue clinical fellowship in pediatric neurosurgery abroad came to Dr. Fairholm's knowledge. He opened the door for Dr. Suryaningtyas to apply to British Columbia's Children's Hospital $(\mathrm{BCCH})$ pediatric neurosurgery fellowship program. As the former Dean in University of British Columbia and neurosurgeon in Vancouver General Hospital (VGH), he asked his colleague, Dr. Paul Steinbok, to receive Dr. Suryaningtyas as his fellow. Under Dr. Steinbok supervision, Dr. Suryaningtyas worked as clinical fellow in BCCH in 2011 [2]. He learned a lot from Drs. Steinbok, Douglas Cochrane, and Ashutosh Singhal in BCCH especially services that were barely exist in Surabaya such as spasticity program and complex craniofacial program. His encounter with other expert from other disciplines enriched him with the understanding of epilepsy surgery, brain tumor, and spina bifida.

With the return of Dr. Suryaningtyas from fellowship, Dr. Bajamal started to give up pediatric cases to him and Dr. Arifin. Dr. Suryaningtyas started to stitch a web of collaboration with other disciplines, the pattern that he learned during fellowship. Developing a collaborative multidisciplinary service for pediatric neurosurgery was never an easy task for Drs. Arifin and Suryaningtyas. Each specialized service has unique requirements. Until now, the service still needs to be polished 
Fig. 3 Dr. Muhammad Arifin (2015)

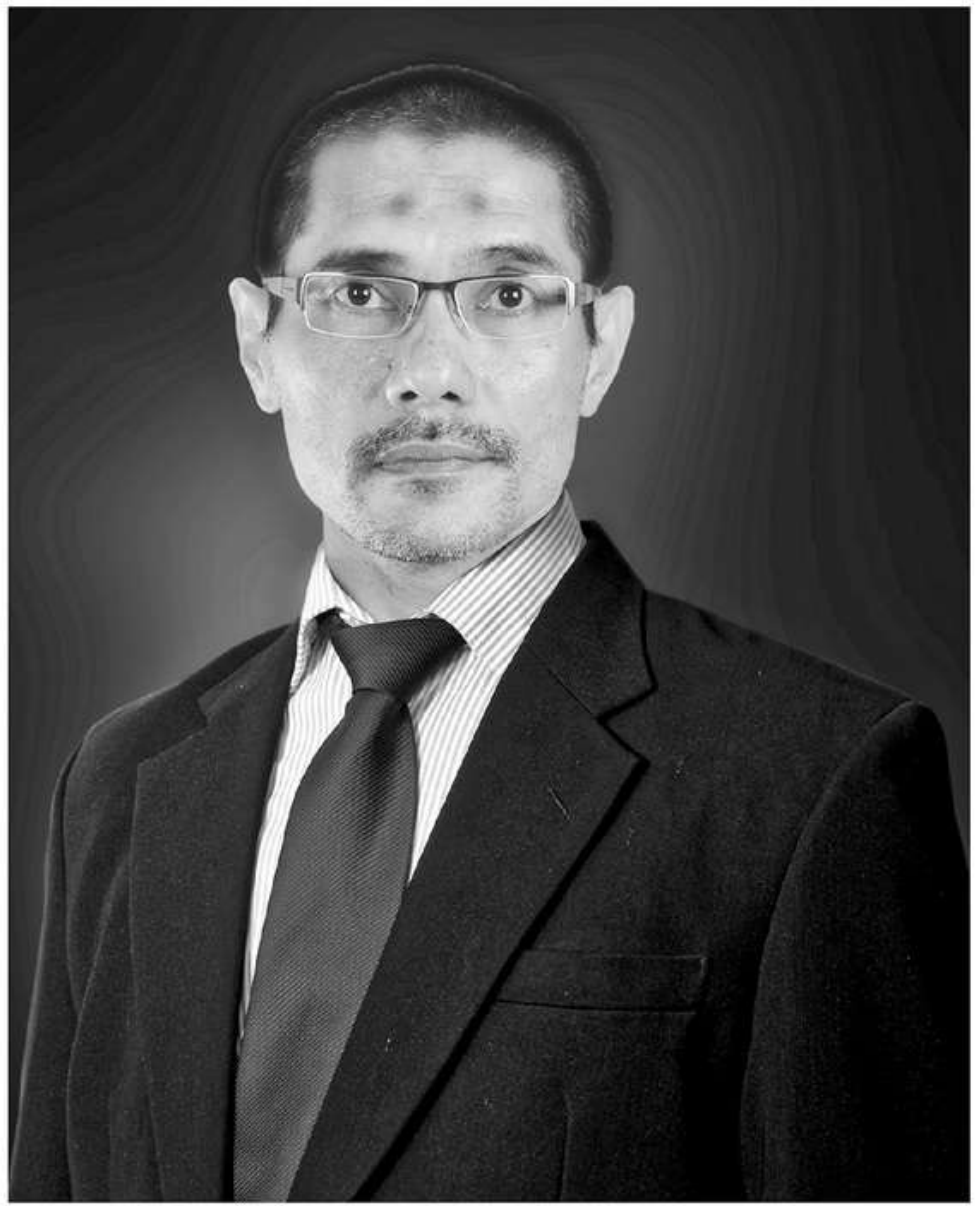

to find its best shape that meets standard with the available facility. Some specialized service is described below. Selective dorsal rhizotomy (SDR) for spasticity was just recently included in the service. Two patients with spastic diplegia underwent SDR procedure with satisfying results.

Nowadays, Drs. Arifin and Suryaningtyas dedicated 80 $90 \%$ of their time taking care of pediatric patients in DSGH with more than 300 surgical cases annually.

\section{Pediatric craniofacial service}

Procedures for anterior/posterior encephaloceles, simple craniosynostosis, and cranial vault reduction cranioplasty are the subject where the neurosurgeon can manage without the team. High prevalence of encephalocele in Indonesia provides the surgeon 75 cases for surgery annually [3]. It has attracted Dr. Eelco Hoving from Netherland to study frontoethmoidal encephalocele pathogenesis for his dissertation supervised by Dr. Wirjowidjojo in 1993 [4]. Procedures for syndromic craniofacial case were discussed and taken care as a team with craniofacial team. The first generation of craniofacial team was built in 1985 with the help of Dr. David J. David, craniofacial surgeon from Adelaide, Australia. All syndromic cases were sent to Australian Craniofacial Unit in Adelaide for surgery. Dr. David regularly comes to Surabaya to meet the team and follows up the patients.

The second generation of craniofacial team was born and started to grow as more disciplines that are involved in patient care. The core team comprises of plastic surgeons (Drs. Magda Hutagalung, Lobredia Zarasade, and Indri Lakshmi Putri), neurosurgeon (Drs. Arifin and Suryaningtyas), and anesthesiologist. Drs. Hutagalung and Zarasade were trained in Australian Craniofacial Unit in Adelaide in 2008, under Dr. David. Dr. Putri just finished her training for craniofacial surgery in Craniofacial Center, Rotterdam, in 2016.

In 2012, we did our first complex craniofacial surgery on 2year-old girl suffered from Kleeblattschädel deformity with satisfying result. Since then, we take care almost all of craniofacial syndrome such as Apert, Cruozon, Pfeiffer, and AntleyBixler syndromes in DSGH. The growing team involves other 
Fig. 4 Dr. Agus Turchan (2015)

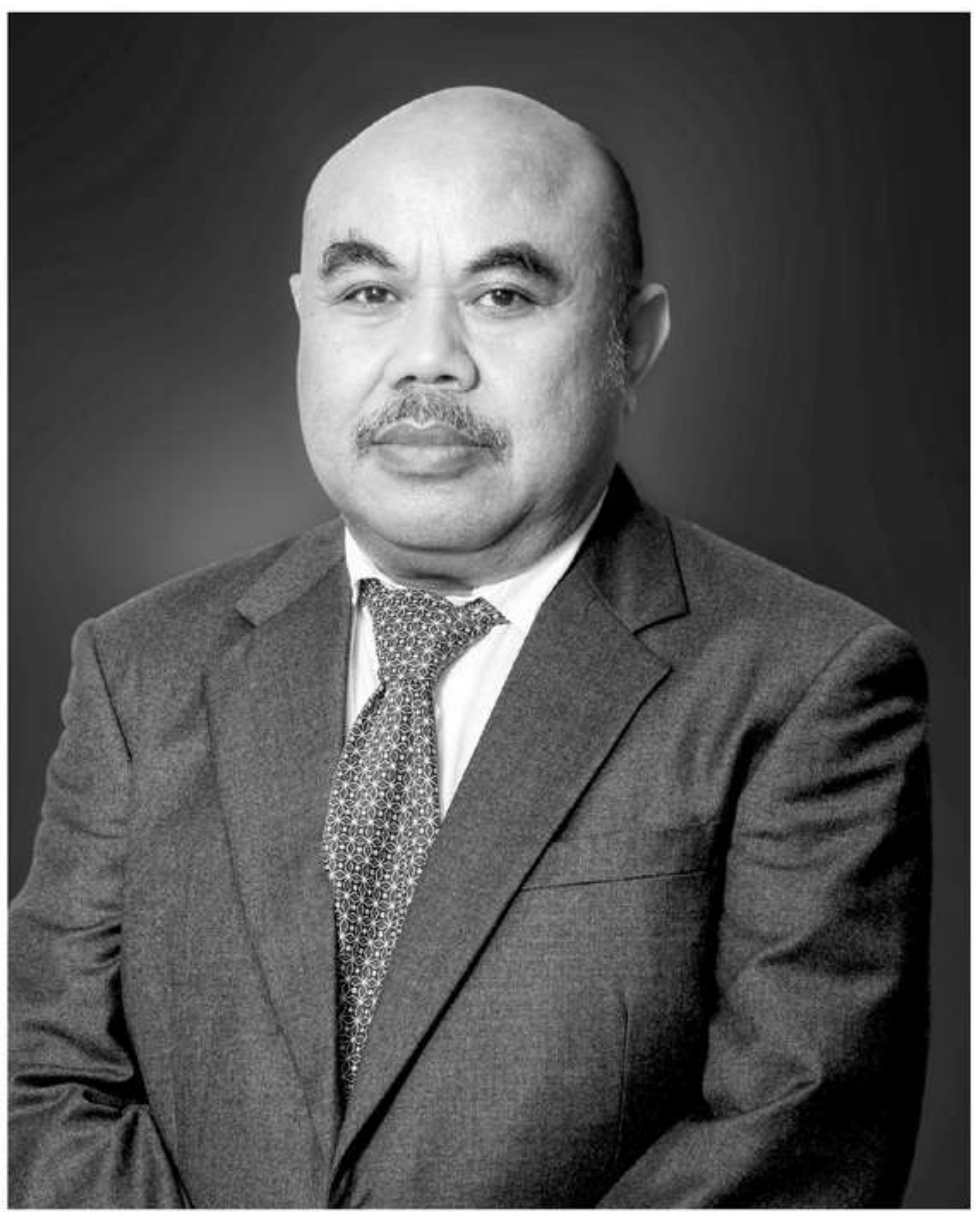

disciplines (ophthalmologist, ENT surgeon, pediatric neurologist, developmental pediatrician, and orthodontist) to address related issues. Dr. Suryaningtyas and the team also work for charity foundation outside DSGH to treat encephalocele and other syndromic craniofacial disease.

\section{Neuroendoscopy service}

In 2006, the first neuroendoscopy equipment arrived in DSGH. Dr. Arifin started the first endoscopic third ventriculostomy (ETV) in Surabaya. Although many hydrocephalus cases were benefited from ETV but the balance of the shunt was not shifted too much. Shunt was still the most frequent procedure for cerebrospinal fluid (CSF) diversion. Today, neuroendoscopy is used in many areas other than hydrocephalus treatment including brain tumor biopsy, intraventricular cyst removal, and endoscopic aqueductoplasty to name a few.

Since CNS infection is prevalent in Indonesia, postinfection multi-lobulated hydrocephalus and intraventricular empyema often present at our service. Neuroendoscopy is used to address the issues. Septostomy for multi-lobulated hydrocephalus is performed to connect the entrapped cavity so that the cerebrospinal fluid can be released with one shunt, later. Intraventricular empyema is addressed using endoscopic lavage [5]. It gives a faster clinical and CSF profile response than giving the antibiotic alone and waiting for the extraventricular drainage (EVD) draining the pus.

We expect that in the near future, the service can expand to c 8 er newer technige such as endoscopic-assisted corpus callosotomy for epilepsy and endoscopic-assisted suturectomy for simple craniosynostosis.

\section{Pediatric epilepsy surgery}

First, epilepsy surgery in DSGH can be traced back to year 2009 when Dr. Suryaningtyas operated on a 10-year-old boy with cortical dysplasia causing intractable epilepsy. The surgery resulted in Engel class 1, ceasing the medication after 
Fig. 5 Dr. Wihasto

Suryaningtyas (2015)

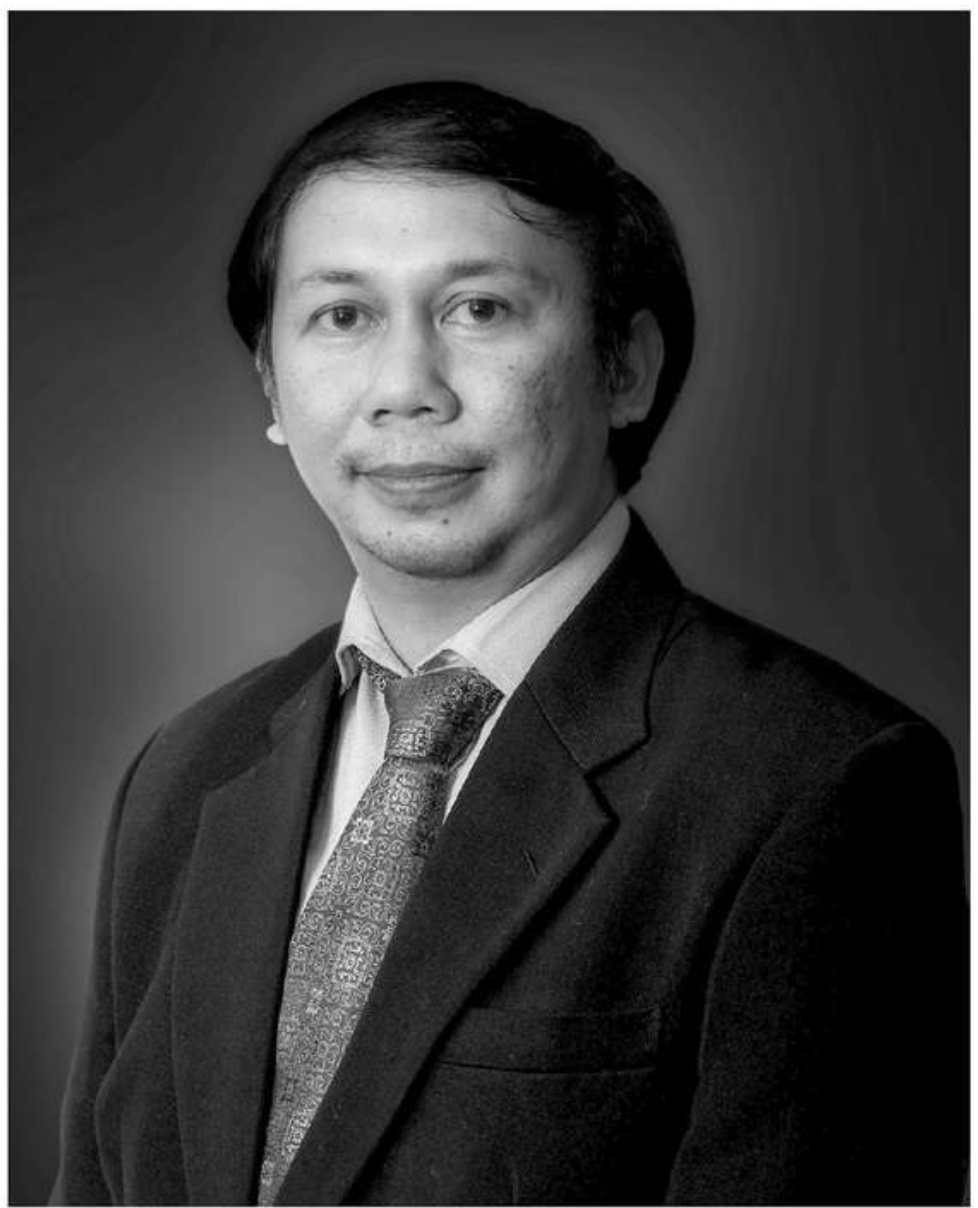

6 months seizure-free. At that time, it was barely possible to set up a complete team comprising neurologists, neuropsychologists, psychologists, neuroradiologists, nurses, neurophysiologists, electrophysiology technologists, and, of course, neurosurgeon. Therefore, we started with a small team of pediatric neurologist/neurophysiologist (Dr. Prastiya Indra Gunawan), neuroradiologist (Dr. Sri Andreani Utomo), and neuropathologist (Dr. Dyah Fauziah). Functional hemispherotomy comprises $40 \%$ of epilepsy surgery and gave the better results.

The other problem with epilepsy surgery is the patient's family refusal to consent for surgery, despite the clear and well-delivered information about the surgery.

\section{Neuro-feto-maternal team}

A formal neuro-feto-matemal program started in 2013. Prior to 2012 , sporadic consultations between the obstetrician and neurosurgeon already took place and there was no formal consensus regarding the treatment of the fetus/newborn. Late response on myelomeningocele would cost the patient with preventable complications. No team was ready when a hydrocephalic baby born.

In 2013, Division of Feto-maternal-Department of Obstetry-Gynecology and Section on Pediatric - Department of Neurosurgery proposed to build a multidisciplinary team and set up a consensus on how to treat a baby with CNS congenital anomalies. The multidisciplinary team comprises obstetrician, neonatologist, pediatric neurosurgeon, pediatric neurologist, developmental pediatrician, physiotherapy, and anesthesiologist. The team comes to work in coordinated fashion for myelomeningocele, intra-uterine hydrocephalus, encephalocele, and intracranial cyst. The long-term purpose of this team is to be the pattern for feto-maternal and neurosurgery services outside DSGH. We are now working on the consensus and treatment algorithm for intra-uterine CNS malformations, 


\section{Pediatric neuro-oncology service}

Pediatric neuro-oncology service (PNOS) is a substantial challenge in almost every aspect outside the surgical premise. Neurosurgical procedure is an essential element for treating neuro-oncology patient. Although CNS tumor cannot rely only on surgical scalpel in many instances, in some cases, the cure can be achieved by surgical alone. To train pertinent disciplines and to discuss all pediatric neuro-oncology patients, monthly meeting between neurology, neurosurgery, neuropathology, and neuroradiology is held routinely. A hindrance in the service comes from radiation oncology. Disparity between supply and demand in terms of radiotherapy service is still pronounced. The patient has to wait at least 2 months to be scheduled. With an increasing referral of pediatric brain tumor cases, the queue becomes longer. Squeezing a slot into already dense service is impossible.

On the other side, pediatric oncology is struggling with chemotherapy regimen since several chemotherapeutic drugs are not available in the hospital formulary. In many cases, they still rely on old regimen. For a kid less than 3 years old with high-grade tumor, there is no way to turn around from oncology service as the age prevents them to go for radiotherapy. Their low nutritional status, the grossness of the tumor, and the compliance of the family add complexity in their recovery.

\section{Residency training program}

DSGH is the teaching hospital affiliated with Universitas Airlangga Faculty of Medicine. Department of Neurosurgery in DSGH started to accept resident in 1982. With the help of FIENS, Indonesia established a structured curriculum for 6 years training program in 1984 . The training program has already graduated 95 neurosurgeons that work all over Indonesia. Before the establishment of sections in Department of Neurosurgery, there was no exclusive rotation for pediatric neurosurgery. Their exposure with pediatric cases were sc 2 tered among adult cases. This training model made general neurosurgeons still easily conceded that pediatric neurosurgeons were the natural caretakers of hydrocephalic, congenital, or myelodysplastic children and, in more generous terms, of children $\sqrt{2}$ h neurosurgical diseases in their first months of life. The technical criterion seems to be more important than the age factor.

In 2008, Drs. Arifin and Suryaningtyas proposed the change of the residency rotation system, especially in pediatric neurosurgery. The proposal to rotate the resident exclusively in one section for a period of time was approved and was immediately in effect. Since then, the resident have a 6month exclusive exposure in pediatric neurosurgery. Usually two or three residents will rotate in pediatric in one period. Residents will also take care of complex pediatric emergency cases. Drs. Arifin and Suryaningtyas warrant every resident to report all the pediatric patients including emergency patient to them. It should be enough for the resident to gain wide spectrum of pediatric neurosurgical problems from "the bread and butter" problems to complex cases. The expectation to widely spread the safe pediatric service by general neurosurgeon in rural area far should be realistic.

\section{Opportunity and challenge}

The only opportunities attributed to our hospital are being the largest referral hospital for eastern part of Indonesia. It has large volume of cases with the opportunity to serve, to teach and learn, and for research purpose and a chance to improve the service with a more complete specialization and supportive team. On the other hand, the facility provided by the government may not be enough to cover all cases in timely fashion. Private sectors are growing to facilitate quick and comfortable service, but the socioeconomic aspect becomes obstacle. Only those who can pay will go to private hospital.

Challenges are far more abundant than its opportunities. Pediatric service at general hospital has to compete with their adult counterpart for resources. Diagnostic measures, operating theater, ICU, radiotherapy, and bedding in the ward are still major concern. It is impossible to do an MRI after work hour. The waiting time for surgery and diagnostic is still considered too long. The neurosurgeon is occasionally pushed to work with the only available imaging (e.g., CT scan). Despite those limitations, we become more creative and skillful without compromising the patient safety as much as possible.

Socioeconomic environment also had a huge impact on the service. Approximately $70-80 \%$ pediatric patient that came to DSGH are from poor family. Low nutritional status, bad hygiene, and difficult access to health facility entail their socioeconomic status. This environment affects the long-term outcome and leaves the relatively high surgical site infections rate unresolved.

Despite all the limitations, pediatric neurosurgery service at DSGH moves forward to continue its efforts in improving the quality, strengthening the collaboration with other disciplines, and keeping the service excellence. We wish to ha 3 a chance to develop a fellowship program in the future and help chart a course for the future of pediatric neurosurgery in Indonesia and ultimately, to improve the care of children with surgical disorders of the nervous system.

\section{Compliance with ethical standards}

Conflict of interest There is no conflict of interest. 


\section{References}

1. Mahatumarat C, Rojvachiranonda N, Taecholarn C (2003) Frontoethmoidal encephalomeningocele: surgical correction by the Chula technique. Plast Reconstr Surg 111:556-565-567. doi: 10. 1097/01.PRS.0000040523.57406.94

2. Steinbok P, Durity F, Kestle J, Cochrane DD (2015) Pediatric neurosurgery at British Columbia's children's hospital. Childs Nerv Syst 31:1419-1427. doi:10.1007/s00381-015-2733-3
3. Richards CG (1992) Frontoethmoidal meningoencephalocele: a common and severe congenital abnormality in South East Asia. Arch Dis Child 67:717-719. doi:10.1136/adc.67.6.717

4. Hoving EW, Vermeij-Keers C (1997) Frontoethmoidal Encephaloceles: a study of their pathogenesis. Pediatr Neurosurg $27: 246-256$

5. Steinbok $P$ (2011) 39th annual meeting of the International Society for Pediatric Neurosurgery, Goa, India, October 16-20, 2011. Childs Nerv Syst 27:1751-1850. doi:10.1007/s00381-011-1524-8 
Development of pediatric neurosurgical service at Dr. Soetomo Hospital, Surabaya, Indonesia

ORIGINALITY REPORT

$7 \%$

SIMILARITY INDEX
$2 \%$

INTERNET SOURCES
$7 \%$

PUBLICATIONS
$0 \%$

STUDENT PAPERS

Ailing Guo, Vigneyshwar Suresh, Xianzhi Liu,

Fuyou Guo. "Clinicopathological features and

microsurgical outcomes for giant pediatric

intracranial tumor in 60 consecutive cases",

Child's Nervous System, 2017

Publication

2

Concezio Di Rocco. "International Education in

Pediatric Neurosurgery", Pediatric

Neurosurgery, 2002

Publication

3 Alan R. Cohen. "Boston children's hospital and the origin of pediatric neurosurgery", Child's

Nervous System, 2014

Publication

Wihasto Suryaningtyas, Muhammad Arifin,

Abdul Hafid Bajamal. "Nasoethmoid-

nasoorbital encephalocele presenting with

orbital pulsation", Child's Nervous System, 
Muhammad Arifin, Wihasto Suryaningtyas,

Abdul Hafid Bajamal. "Frontoethmoidal

encephalocele: clinical presentation, diagnosis,

treatment, and complications in 400 cases",

Child's Nervous System, 2018

Publication

6 epilepsyfoundation.org

Internet Source

7 link.springer.com

Internet Source

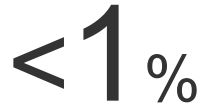

8 documents.mx

Internet Source

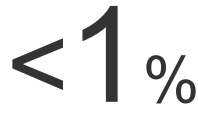

9 "XXI Biennial Congress of the European

Society for Pediatric Neurosurgery, 11-15 May

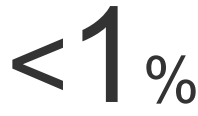

2008, Montreux, Switzerland", Child s Nervous

System, 05/2008

Publication

10

Tucker, O.P.. "Bilateral Wilms' tumor", Journal

of Pediatric Surgery, 198612

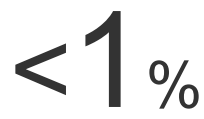

Publication

11

"Biomaterials and Medical Devices", Springer

Nature America, Inc, 2016 
Exclude quotes

On

Exclude matches

Off

Exclude bibliography

On 